\title{
Objectives of the Review of Evolutionary Political Economy's 'Manifesto' and editorial proposals on world problems, complex systems, historico-institutional and corruption issues
}

\author{
Phillip Anthony O'Hara ${ }^{1}$
}

Received: 6 November 2020 / Accepted: 22 March 2021 / Published online: 12 April 2021

(c) European Association for Evolutionary Political Economy 2021

\begin{abstract}
This paper presents results of a close textual analysis of the Review of Evolutionary Political Economy's (REPE's) 'Editorial Manifesto' (Cincotti et al. Rev Evol Polit Econ 1:1-12, 2020), with special reference given to journal objectives, including making proactive editorial proposals for promoting, deepening and potentially modifying such objectives through time. In the process, it isolates six main objectives of the journal, including publishing papers on the big issues of the day using evolutionary themes; questions of integration and unification of schools and trends; studying the process of change through complex-systems, history and other methods; utilizing trans-, multi- and interdisciplinary perspectives; deepening international political economy (IPE) concerns within post-Keynesian and institutional schools; and scrutinizing differences between the schools and trends of evolutionary political economy (EPE). Ten proactive editorial proposals are made to mostly promote or in some cases adjust objectives. For instance, it suggests that special issues on big issues/problems apply especially EPE concepts and principles in some detail. It argues for papers on linkages between complexity theory and circular and cumulative causation. It encourages research on the positive and negative processes of innovation through the prism of the instrumental and ceremonial functions of technology and institutions. It suggests deepening an understanding of historical specificity and evolution vis-à-vis change and metamorphosis. It recommends scrutinizing the differences between trans-, multi- and interdisciplinary analyses; strengthening the IPE dimensions of all schools and trends of EPE; and encouraging papers on the emergent relationship between micro-meso-macro-global real world processes. It stresses the need to assess periodically the relative power of various schools and trends of EPE, and of publishing independent papers about editorial directions and problems. It outlines forms of editorial corruption of objectives and how they may be prevented or moderated, and proposes that objectives be kept firmly in mind when eliciting, refereeing and assessing awards, papers, symposia and special issues. Lastly it proposes the establishment of an independent Editorial Ombudsperson or committee
\end{abstract}


for resolving disputes and anomalies; regular communication between REPE editors, boards and others on critical issues; and the publishing of yearly, five-yearly and decadal reviews and reports concerning progress with objectives for the journal.

Keywords REPE $\cdot$ Journal objectives $\cdot$ Problems and policies $\cdot$ Concepts and principles $\cdot$ Integration and convergence $\cdot$ Change and evolution $\cdot$ Editorial proposals $\cdot$ Editorial corruption

JEL classification B52 $\cdot \mathrm{I} 23 \cdot \mathrm{P} 16$

\section{Introduction, including brief statements of REPE's objectives}

It is great to see the emergence of the first three issues of $R E P E$, to restart the process of (re)constructing an evolutionary political economy (EPE). Most readers of REPE, I am sure, are delighted to read the stimulating 'Editorial Manifesto', 'Towards an Evolutionary Political Economy: Editorial to the Inaugural Issue of the Review of Evolutionary Political Economy REPE', written by Silvano Cincotti, Wolfram Elsner, Nathalie Lazaric, Anastasia Nesvetailova and Engelbert Stockhammer (Cincotti et al. 2020). In it, several core issues are raised about the future development of the journal. Most readers are also likely excited to read of the manifesto's desire to have ongoing constructive feedback of core issues for deepening the journal's community of understanding of EPE and ways of enhancing it.

As the editors say, 'to be successful, this journal needs critical feedback from critical scholars', as the 'editorial team always welcomes comments on REPE's agenda and issues' (Cincotti et al. 2020: 8; emphases added). As a member of the International Advisory Board, having published more than 100 papers in journals/edited books, over a dozen volumes of books and special issues of journals, and written close to 800 referee reports, I felt it is my duty to provide detailed comments, since I had suggestions for being cognizant of promoting and through time likely adjusting the journal's objectives. Reflections by readers, writers, referees and advisors associated with the journal, now and in the distant future, on the nature of the journal, set down for all to see in a normal issue of the journal, will likely be critical to its successful development and progress. This is especially true of the democratic style of governance and participation required for such a potentially progressive institution, as the journal is hoped to become.

This paper presents the results of a close textual analysis of the editorial manifesto regarding its main objectives, and how they can be realized or improved upon now and into the future. The editorial manifesto of the REPE sought to (a) introduce the journal to its readers, (b) discuss objectives and (c) detail aspects of these objectives and other issues. The manifesto thus had many things to say in a short space. It also had to stimulate the reader so that they could get through the paper in an enjoyable fashion. It thus wasn't going to state objectives specifically, or with logic-math equations, but was rather likely to treat objectives in a typically literary style. The manifesto was meant to stir readers into action (getting them to read 
papers, write papers, referee, provide advice and propose special issues) more than merely enabling them to understand the logical reasoning behind their arguments concerning objectives. As a consequence, the main objectives were often not much 'emphasized, highlighted and repeated', i.e. detailed, in the manifesto. Readers are thus unlikely to have easily noticed and remembered them all.

This is where this current paper comes in. My objectives here are quite different from the manifesto in aggregate since, firstly, I want to be very specific about such objectives, secondly, to comment on them, and, thirdly, provide editorial suggestions regarding them. I delimit the scope of this paper to these three issues. However, due to the literary style of the manifesto, and its general aims (e.g. introducing readers to the journal), it was difficult to ascertain its main objectives and to contextualize them, merely through reading the paper (plus the 'Aims and Scope') several times. I realized much work would be needed to understand the objectives, and for this task I utilized several tools associated with a close textual analysis. Firstly, I employed 'multiple readings': reading fresh copies of the manifesto seven times over the period of seven weeks, using highlighters to isolate main points. Secondly, I did a 'keyword analysis': where different color highlighters isolate different aspects of objectives, such as isolating specific objectives, the context of objectives and ways objectives are to be put into practice. Thirdly, I used 'contextual mapping': where the context of objectives was discussed, including how objectives relate to each other. Fourthly, I read the CVs and some papers of the writers of the manifesto to understand the objectives in more detail. Fifthly, through a circular process, I was finally able to delineate the specific objectives ('objectives separation'), as well as to holistically link the objectives together in one paragraph so they made sense ('objectives aggregation plus context'). which took a lot of rearranging to complete the task.

The final result of all this close textual analysis of objectives is to provide, firstly (1), a short paragraph/sentence statement of objectives of the journal (here and elsewhere below); secondly (2), in this section, to outline these six objectives separately; thirdly (3), in the subsequent sections of this paper, to state the respective objectives in more detail (citing the manifesto); and fourthly (4) to elaborate on them and provide ten proactive editorial suggestions vis-à-vis the objectives.

In the rest of this section, we merely summarize the results of the close textual analysis of the editorial manifesto. Then, in subsequent sections, we (a) specify the objectives with contextual evidence from the manifesto, (b) discuss various aspects of the objectives and also (c) provide ten proactive editorial suggestions for promoting, deepening or modifying/critiquing such objectives.

The first thing to do is to present a very summarized paragraph of the objectives, where the six main objectives are situated, in aggregate, as follows: REPE's ambitions are to (1) (re)construct an EPE by examining pressing world problems and policies (2) using evolutionary PE themes; (3) stimulate potential convergence and unification of the schools and trends while (4) studying the evolution of complex systems and historico-institutional trends; and (5) scrutinize differences between the schools/trends and (6) apply trans-multi-interdisciplinary methods of analysis.

The second thing to do is to state the six objectives in a little more detail, prior to documenting them more thoroughly with textual evidence in subsequent sections: 
Objective 1 is a clear desire to publish 'cutting-edge' research on critical 'topical' world problems, issues and policies, i.e. the 'big political-economic issues of today and tomorrow' (p. 7). Some of the applied issues, problems or policies mentioned in the manifesto include 'innovation, networks, distribution, or social class [and] climate change', as well as 'economic crises, inequality, ... unemployment, ... financial instability, digital transformation, artificial intelligence, ... environmental degradation, ... climate change ... [and] epidemics' (p. 8).

Objective 2 is a determination to examine these problems, issues and policies through the prism of various 'heterodox-pluralist evolutionary and complexity perspectives', including, for instance, 'institutional analysis, critical political economy, heterodox macroeconomics, computational methods, and interdisciplinarity' (p. 8). Editors are here alluding also to the future contributions of original institutionalists, neo-Schumpeterians, post-Keynesians, neo-Marxists, feminists and ecological political economists.

Objective 3 seeks to promote discussion, interaction and potential integration (p. 1) and convergence (p. 4) among the various schools and trends of EPE. It is dependent upon the success of the other objectives (especially 1 and 2) leading to successful work on this third objective and is closely linked to the fourth objective:

Objective 4 seeks to study and comprehend the process of change (p. 2) in real political economies, as well as schools of thought and perspectives, as they evolve through time in multifarious forms. This can be done, for instance, by the use of complex-systems analysis or historico-qualitative methods, or some combination of formal and qualitative methods (p. 2).

Objective 5 states that 'interdisciplinary' (pp. 1, 3, 7, 8), 'transdisciplinary' (p. 2) and 'multidisciplinary' (p. 5) themes should inform many issues in EPE. One such theme emphasized in the manifesto is for especially post-Keynesian and Veblenian strands of EPE to incorporate international political economy (IPE) (p. 7) processes, problems and concepts into their edifice, so they are situated in a national-regionalglobal context of international relations and economics.

Objective 6 is interrelated with concern for potential convergence and integration, since it deals with differences (p. 4) within and between the schools and areas of EPE. Some of the differences may be crucial, especially relating to positive and/ or negative scrutiny of innovation (pp. 3-4); the role of individuals, and/or sectorsindustries, groups and systems; formal complex-systems and/or qualitative historical systems (p. 2); and the degree of realism (p. 4) of micro-meso-macro-global models and simulations.

Since it took me seven readings of the manifesto over seven weeks to delineate specifically what I think the objectives of REPE are, I don't expect others to be able to understand them clearly from reading the manifesto in a single read, or even a double read. But there may be scholars among readers of REPE who understood them very quickly and easily; and some may disagree with my delineation of objectives (but see below for more details about them). Indeed, if I had done nothing else but delineated them, I would have been happy, given the effort required. But I have two other tasks to undertake. Firstly, I have to give some idea as to how I arrived at the six objectives, which is done in successive sections below. Plus I have to contextualize them, show how they are linked (at least to some degree). If I had just 
done these tasks (not only stated/delineated objectives but also explained how the text evidenced them, and contextualize them), and nothing else, I feel I would have achieved something significant. But I do have other tasks to undertake: for instance, making certain proactive editorial suggestions for the future workings of the journal in light of objectives. Some such suggestions will be more theoretical and others more strategic and administrative. Also, I leave it for others to provide details on and to critique these theoretical and administrative suggestions, by concentrating on them, for instance, in subsequent papers, since here, I can often merely just scratch the surface, given space limitations.

So what the reader should expect in the rest of this paper is not a thoroughly exhaustive account of (a) how the text provides evidence for the objectives, nor for (b) how the objectives are contextualized, and not even for (c) suggestions about the future workings of the journal. Rather, you can expect notes whose purpose is to stimulate thinking, debate, discussion, criticism, writing, editing and contributing to editing and advising vis-à-vis REPE. We thus undertake these tasks with a thoroughly humble purpose in mind, merely to open the minds of readers to thinking about these issues, and for them to act on or criticize/reconstruct these arguments. It is in this context only that we investigate these objectives sequentially through the next few sections. As the paper evolves, we introduce various proactive editorial proposals (ten in all) for advancing or modifying the objectives. In the last main section, we scrutinize the potential for systemic editorial corruption of objectives and ways of preventing or limiting this. A conclusion summarizes the whole argument.

\section{Objectives one and two}

\section{1 (1) Critical issues/problems and (2) themes/perspectives of EPE}

In this and subsequent sections, we elaborate more on the objectives and provide editorial suggestions. In this context, objective one is to promote pluralistic-heterodox excellence in addressing topical and critical issues, problems and policies, while general objective two is to use evolutionary-complexity themes and methods in addressing these topical issues/problems/policies in political economy. As was stated in the journal:

The ambition of the journal is ... to become a pluralistic forum of excellence in what is emerging as [evolutionary] political economy[.] ... [T] he editorial team of REPE, EAEPE, and Springer did identify a space indeed for a new pluralist-heterodox journal, which relates cutting-edge evolutionary and complex systems with institutional analysis, critical political economy, heterodox macroeconomics, computational methods, and interdisciplinarity, in a number of applied fields, from innovation, networks, distribution, or social class to climate change, with topicality and critical policy relevance, wherever possible. (Cincotti et al. 2020: 1, 8; emphases added.)

This is an ideal double-headed objective for the journal, and we can anticipate in the future editors, board members, writers and readers scrutinizing the extent to 
which the journal's papers and special issues do concentrate on publishing papers that evaluate core problems/issues of the world in a topical and policy context, and from various evolutionary political economy perspectives. The editors and publisher need to be congratulated for using this theme as a point of departure for the journal.

The first objective thus relates to core problems and policy issues; and the second links to doing this within various frameworks/methods of EPE. We start with the first of these. We have already mentioned a dozen topical areas worthy of scientific scrutiny in the journal, as mentioned in the manifesto. In addition, the editors have already completed, organized or planned special issues of the journal on problems, issues and/or policies on (1) 'Work, Environment and Planetary-Scale Computation in Political-Economic Evolution', (2) 'Financialization', (3) 'Network Dynamics, Economic Transition \& Policy Design' (including innovation) and (4) ‘Agent-Based Macroeconomics in [an] Era of Global Crises: Innovative Policy Measures for an Adaptive Resilient Economy'.

One referee suggested that the feasibility of possible special issues I will soon mention should be ascertained and discussed. Their feasibility links to three factors. Firstly, how important they are: they are all crucial global-regional issues; therefore, certain people with the knowledge and potentially the skills will likely be excited to develop them. Secondly, the publishing and editorial expertise and opportunities are present to assist such scholars with an enthusiasm and the skills to develop the special issues. And thirdly, readers are likely to find successful such special issues to be highly interesting and worthy of reading and linking into their research. Otherwise, it is up to people reading this paper to act on such suggestions and develop a set of themes and search for writers to activate the special issues.

At the onset, though, I have to stress, as another referee of this paper emphasized, that the quality of the work published by REPE is ultimately dependent upon the agency of the editors, interests and skills of its writers, quality of the referees, capacities of the publisher, proactive nature of readers and the energy of people with knowledge to commence a special issue and go through the job diligently to the end for possible 2-3 years or more. What I, as Advisor, have to suggest in terms of special issues may not equate with what people can do, or want to do for this journal, despite the inherent quality of the topics. Nevertheless, some appropriately skilled readers of this paper may be stirred into action by reading this list of important topics for special issue development; and I therefore propose them in this collaborative writer-reader context, and as a member of the International Advisory Board of REPE.

The first core applied topical and policy field which could be investigated in a special issue includes global and regional economic, financial and social crises, including the ongoing coronavirus global crisis, which is currently generating depressions and deep recessions in most areas of the world. We will, of course, need at least one special issue of the journal on this global coronavirus crisis. However, since dozens of journals will be doing the same, it is crucial to ensure that the global coronavirus crisis special issue is done in accordance with the objectives of the journal. A first special issue on the coronavirus crises could be a more general one, dealing with practical ongoing issues, with linkages to various aspects, principles and concepts of EPE. But a second special issue (or series of papers), done if 
and when the issue has long past its emergency/crisis phase, could be more insightful, including more elaborate data, historical context and sophisticated theory and empirics. This is an area of interest to all evolutionary political economists, including social, institutional and development/international PE scholars with an expertise in epidemiology, community health, geopolitics and institutional-governance issues; post-Keynesians, Schumpeterians, and agent-based computationists with an interest in linking the crisis to growth, employment and innovation issues; plus others, such as ecological and feminist EPEs, could join in to promote the objectives of the manifesto.

A second core area of topicality and policy relevance is the current diverse state of governance and performance in the world; for instance, with special reference to the most problematic region: sub-Saharan Africa. This is critical since it is arguably one of the major areas of the world yet to undertake widespread and sustainable ongoing socioeconomic progress. It is of special concern for Europeans, who are on Africa's doorstep, and have been seriously implicated in Africa's difficulties in generating sustainable quality of life and standard of living for its human and non-human populations. These issues are also uppermost in the mind of the multitudinous African diaspora around the world; plus development scholars, global and regional institutions; and domestic/regional bodies that have battled in the face of colonial/neocolonial path dependence, African corruption, inadequate institutions, jihadists, protracted diseases, poverty, transnational power structures and other anomalies. In this context, we are all well advised to read and act on the outstanding book by Rodney (1972: chs 3-6) on How Europe Underdeveloped Africa, and contribute to rectifying the situation.

In the process, the journal could also investigate the case of partially successful African governance in, for instance, Botswana and to a much lesser extent Ghana, and why such success has faded somewhat over recent decades. This is an area where all the major schools and trends in EPE could participate, given the 'systemic' nature of the problems involved. REPE could also help its editors, advisors, writers and readers learn a lesson of how the journal can be less an avenue for self-promotion, in the cut-throat world of US-European academic survival, and more a pathway for comprehending political-economic evolution, and propelling quality of life for Africans, especially through an application of core EPE principles and concepts.

A third core area for special-issue treatment in the journal is global monetary and fiscal policy. Special emphasis could be placed on the nature and critique of modern monetary theory (MMT), and the extent to which it is currently being activated in the national and international contexts (much more detail is needed on multiple-nations beyond the USA). The scholarly heritage of MMT emanates from, as Wray (2015) notes, J.M. Keynes, Karl Marx, Georg Knapp, Abba Lerner, Hyman Minsky and others, while the main principles or concepts are said to be those of functional finance, taxes drive money, sovereign governments not needing to borrow currency to spend, the purpose of government bond sales being to impact interest rates, and banks creating money when they make loans. Such a special issue should of course note some potential problems with MMT, including those associated with the Phillips curve, open economies and financial stability (see Palley 2015). These issues could be linked to (inter)national money, central banking, economic crises 
and changing fiscal-monetary policies. Post-Keynesians and numerous others are working in the area, including institutionalists and neo-Marxians, while feminists and Schumpeterians could join the discussion, as well as ecologists to embed issues of MMT, money and credit into climate change and declining biodiversity issues (see e.g. Nesvetailova and Palan 2013; Nesvetailova 2005).

A fourth core issue, concerning problems of the world that would likely elicit much interest concerns the 'Wealth of Some Nations' (as Caldwell 1977 called 'it'). A special issue on this topic could include surveys of the wealth/income of (sub)nations and regions in a global-historical context. It could also be disaggregated to include gender, class and ethnic distributions. Monetary wealth/income could be compared with quality of life, innovation, climate change, ecological footprint, health, crime and happiness indices. One could also analyze the differences between flows and stocks vis-à-vis income and wealth. A mixture of EPE influences comprising feminist, social, institutional, ecological, post-Keynesian, neo-Schumpeterian and neo-Marxian principles and concepts (some of them fused) would be especially capable of making this a fascinating volume or series of papers.

These four areas, chosen merely as important examples to encourage innovative application of the main objectives of REPE, would be major achievements if they were published in the journal, as special issues, symposia and/or a series of papers through time. We raise the question now of how these empirical and critical problems could be scrutinized. REPE could emphasize the potentially integrated ensemble of several heterodox/pluralist evolutionary influences discussed in the manifesto. It could analyze these core problems and issues using core concepts and principles of EPE.

Proactive editorial proposal one It is recommended to evaluate special issues, plus papers and symposia, and generally topical issues, problems and policies, through the application of core EPE concepts and principles. This should promote objectives 1 and 2 and thereby help to generate alternative, comparative, discourse to the conventional wisdom of principles of economics.

This also raises the question of whether different forms of EPE share similar concepts and principles, and how we can encourage the development of a more converging-complementary conceptual edifice into the future. This leads us to the third objective of the journal, a most difficult one (along with objective 4): integrating various styles of evolutionary political economy.

\section{Objective three}

\section{1 (3) Integrating (converging) evolutionary political economies}

The third objective is to integrate various schools, perspectives and methods within the edifice of heterodox/pluralist EPE, viz: 
The ambition of the journal is to bring together and integrate political economy, evolutionary and institutional economics, agent-based computational economics, and heterodox macroeconomics[.] ... It is for such boundarycrossing research that REPE will be a forum. ... We think it is important to build more bridges between these and also other heterodox approaches ... that could at some point absorb and replace the orthodox economic mainstream[.] [A] key purpose of $R E P E$ is to being together different heterodox contributions[.] (Cincotti et al. 2020: 1, 6, 7, 8; emphases added.)

Building bridges between the main trends and schools of heterodox-pluralist EPE is a difficult task, but one that is important for successful progress of the journal, as it is arguably a most challenging scholarly objective.

In this context, brief mention should be made of some of the extant attempts to integrate such themes, as a reminder to those considering this third objective (hopefully linking it to objectives one and two). Again, I will not be exhaustive here, for this is the task of those writing whole papers on the subject. I merely point you in what I hope is the right direction.

Firstly, there are those who have tried to consolidate certain themes within two (or three) areas or schools of heterodoxy. These include various scholars, such as Dillard (1980), Wilber and Jamieson (1983) and Whalen (2011), who developed aspects of post-Keynesian institutionalism. Dugger and Sherman (2000), among others, explored linkages between original institutionalism and neo-Marxian PE. Jennings and Waller (1991) probed integrative themes within feminist and institutionalist schools. While Dow (2020) integrated various themes of feminist with post-Keynesian and neo-Schumpeterian PE. Certain scholars have also examined interactions between complexity and neo-Schumpeterian analyses (e.g. Arthur 1994; Foster and Metcalf 2001); attempts to interfuse elements of post-Keynesian with neo-Schumpeterian PE (as mentioned in the manifesto; e.g. Dosi et al. 2010); plus post-Keynesian hypotheses/theories being utilized in agent-based computation (e.g. Mazzocchetti et al. 2018; Raberto et al. 2019). In addition, some scholars have analyzed the comparative degree of community of interactions, for instance, between Feminist Economics and other journals of heterodox and orthodox economics (see, e.g. Lee 2008; Woolley 2008).

It is important also that the journal not try to reinvent the wheel vis-à-vis potential convergence and integration, since some authors and editors have already attempted to integrate themes from a myriad of schools/trends of EPE (see some earlier work by, e.g. Dillard 1982 and especially Fusfeld 1988). For instance, O'Hara (1999, 2007, forthcoming) developed integrative institutional-evolutionary principles linking certain trends within complexity, institutional, neo-Marxian, feminist, neo-Schumpeterian, post-Keynesian and ecological schools/trends. These principles include historical specificity and evolution, circular and cumulative causation, complexity, heterogeneous groups and agents, contradiction, uncertainty and instrumental valuation (among others). Lee (2018) developed a coherent heterodox microeconomics combining aspects of different schools such as post-Keynesian, neo-Marxian, Sraffian, social and feminist. Also, Jo et al. (2018) explored some interactive themes within and between the major schools of thought, most especially 
institutional (including new), neo-Marxist, feminist, social, ecological and postKeynesian thought.

Further studies in the journal can detail these and other attempts at cross-fertilization, while providing their own hypotheses and studies to scrutinize interaction, potential convergence and integration into the future (or criticisms thereof). However, as the second objective indicates, the journal will need to go further than simply loosely applying some EPE ideas to timely problems and policies of the contemporary world. There will need to be a rigorous application (including specificity) of core concepts and principles to problems and policies; and furthermore, some progress towards potential interaction, convergence and integration of heterodoxpluralist ideas within and between not only two but possibly three, four or more of the evolutionary schools/trends/methods (objective 3 ).

The main point is that unless EPE can reconstruct a series of well-established and applied concepts and principles of political economy, it will not be able to become established as the mainstream that it seeks. I recommend that we not talk so much about themes and ideas so much but rather that we emphasize, be more cognizant of, and explicitly develop and apply, concepts and principles, and furthermore, that we write not only many research monographs but also some well written and applied textbooks on Evolutionary Political Economy Principles and Applications. Unless and until we can do this, and have successive generations of students and scholars inculcated in them, EPE will not develop sufficiently to challenge the mainstream at all; it will not even come close to achieving that. But we must go beyond mere principles and concepts of one school (e.g. Hanusch and Pyka 2007), although this will likely help in the long run, if others are doing it with related schools, and if they can finally come together. We should not do what many do, in calling the paper or book 'principles' while not mentioning the word after the front cover/foreword (as done by Nilsson 1982), or unwittingly including political economy principles but only citing policy or neoclassical principles (Fusfeld 1988). I suggest we need to specifically differentiate between evolutionary political economy concepts, principles and other categories and apply them in different ways to core world problems.

\section{Objective four}

\section{1 (4) Complex systems plus historical specificity and evolution}

Being an evolutionary science, EPE seeks to analyze the process of change, metamorphosis, transformation, mutation and innovation through the emergence of novelty and new arrangements of systems within the political economy. The manifesto indicates that this can be done in a number of ways, especially through scrutinizing the history and evolution of socioeconomic systems through the use of complexsystems analysis or through qualitative (e.g. historical) methods, or both. As the manifesto says:

The ambition of Evolutionary Economics in general is to interpret change and to observe the development (or history) of socioeconomic systems, either by 
a formal dynamic system or by its qualitative reconstruction (or by both). ... Complexity economics is the answer to the needs of understanding all that ... (Cincotti et al. 2020: 2,4).

Advancing complexity theory and its applications is an important objective of the editorial manifesto, and some of the authors of the manifesto have published core works in the field (e.g. Farmer et al. 2012; Nesvetailova 2014; Elsner et al. 2015). Complexity was also the theme of the 2002 EAEPE Conference in Bremen. Indeed, one could interpret the manifesto as indicating, in several places, that REPE should, where appropriate, adopt a complexity approach in its papers, as a core objective, and push forward to apply it to several problems in the world.

One important aspect of complexity theory is that the world is indeed a complex place, so that simplistic theories or approaches are unlikely to apply to political economy processes and problems (hence the limitations of Occam's razor). The main reason for this is the interrelated or interdependent nature of political economy processes. Single factor theories are unlikely to hold in such a complex world of multi-causal processes, especially in detailing emergent transformations from microto meso-, macro- and global dimensions of problems, in which we cannot easily distinguish between independent and dependent variables. The causes of problems tend to be circular as well as cumulative, which tend to lead to amplified dynamics (positive feedback) of cycles, waves and phases of evolution, as well as some negative feedback processes in some instances, which leads us to the Veblenian, Kaldorian and Myrdalian principle of circular and cumulative causation (CCC).

Proactive editorial proposal two A theme that needs encouragement in the journal is to examine the relationship between complexity and CCC, especially as applied to core world problems and schools of thought in EPE. CCC is used by all schools and influences within EPE, most explicitly by Veblenian institutionalists and postKeynesians (see Berger 2009). Scrutinizing the relationship between complexity and CCC could thus promote objectives 3 and 4; and applying them to specific issues and problems could advance objectives 1 and 2 .

A second important aspect of complexity theory is that real-world processes are emergent, in the sense that micro-processes are usually quite different from emergent meso-dimensions, which in turn help other emergent cumulations to arise through the macro and further to global dimensions. The macro-global problems of the world, such as systemic crime/incarceration, poverty, development, un(der) employment, climate change, war, policy, coronavirus crises, financial instability and wealth generation, tend to be the outcome of a whole series of interrelated factors that emerge sui generis, cumulatively or holistically from the sub-systems.

Various forms of complexity theory may also be an obstacle to tackling the world's problems. The manifesto examines one such form of neo-Schumpeterian complexity theory that may be problematic in this respect, especially where the positive factors are emphasized in the innovations rather than the negative effects and processes. For them, the key elements to consider include providing an environment for innovation; stimulating process, product, market, raw material and industry 
reorganization (Schumpeter 1912: 63-66); linkages between invention and innovation; the role of finance; networks of innovation that undergo evolution through areas, nations, clusters, commodity chains, and corporations; routines and habits; and productivity generated through economies of scale and scope, agglomeration, new ideas in action and research and development. These are potentially positive elements of new ways of doing things.

The editorial manifesto recognizes, though, that there are other aspects to consider that are not so potentially positive. These include, for instance, innovations that kill thousands of people during war; that lead to monopoly power in the longer-run; that generate many deaths and sickness on the job (or with consumers); that enhance pollution and climate change; that accentuate gender, ethnic and class distinctions; that exacerbate speculative bubbles, periodic crashes and recessions; and that reinforce core/periphery/semi-periphery uneven development.

These multifarious new technologies and institutions can thereby be viewed through a third core aspect of complexity theory, the principle of contradiction and creative destruction, involving not only the creative/positive (innovation, productivity, etc.) but also the destructive/negative (instability, unemployment, etc.) processes affecting the world and its regions (see Marx \& Engels 1847-48; Schumpeter 1947). The editorial manifesto relates this contradiction to the neo-Veblenian concept of the instrumental (positive) and ceremonial (negative) functions of institutions and technology. ${ }^{1}$ These types of potential dysfunctions are also examined by other schools and theories of EPE (e.g. see the 'contradiction work' of Stockhammer 2013; Bernardo et al. 2016; Nesvetailova \& Palan 2013).

Proactive editorial proposal three $R E P E$ should encourage the publication of material that recognizes the complexities of the instrumental-ceremonial contradictions and creative destructions involving techno-institutional innovations, which should enhance the objectives concerning pragmatically analyzing problems through evolutionary perspectives, and promoting the convergence and integration of various traditions of EPE.

The 'other part' of this objective relates to the use of qualitative methods of examining change and metamorphosis. Historical analysis is mentioned, perhaps emphasized, in the early part of the manifesto, and some of the manifesto's authors have done some good work on historical specificity and evolution (e.g. Lazaric et al. forthcoming; Nesvetailova \& Palan 2010; Stockhammer et al. 2019). Some authors in the first volume of REPE also demonstrate excellent examples of historical specificity and change applied (e.g. Toporowski 2020 and Arestis 2020). Despite this, the principle of historical specificity and evolution, defined as postulating that significant economic theory must have, firstly, institutional and historical content, and

\footnotetext{
1 Two questions arise here. Firstly, why were Tool and Bush (e.g. 2003) not cited in REPE's manifesto; nor any other Veblenian institutionalist not an editor of $R E P E$; even though instrumental value theory/ neo-Veblenians are (abstractly) much discussed in the manifesto? Secondly, most of the Manifesto's 'References' are to neo-Schumpeterian, complexity and post-Keynesian political economy. Why?
} 
secondly, historical-evolutionary context and metamorphosis, is seriously underplayed in the Manifesto.

As the manifesto progresses EPE seems to be all about theory and problems per se, when such theories and problems should be seen through an historical and evolutionary context (see Mills 1959: chs 1,8). The 'thing' that makes EPE evolutionary is the process of real change through historical time. Historical time linked with geographical space; heterogeneous groups and agents; plus institutions, innovation, habits and routines: in combination, all these represent the multi-dimensional complexity within which the real world of political economy processes evolve. Metamorphosis through innovation and technology; phases of evolution and change; business cycles, waves and financial crises; and changing aspects of social, health and infrastructure capitals: all these evolve through real historical time. Without historical time, there is no evolutionary political economy, either in theory, practice or empirically.

Proactive editorial proposal four REPE papers and editorials should, where possible, emphasize change, mutation, variety through complex systems analysis, especially historical-temporal inquiry/context, plus other suitable means of heterodoxevolutionary quantitative and qualitative analysis.

History and evolution has relevance for micro-, meso-, macro- and global dimensions of capitalism and other economies. The more expansive our vision of time becomes the more we move from the micro through to the global. In the short run, we may have only prices that change, but in the long run capital can be expanded, while in the longer-term technology changes, and in the secular period all major institutions and ideologies undergo metamorphosis. It is time to put history back into theory, by incorporating into EPE: Karl Marx's structural history of capitalism; Thorstein Veblen's phases of evolution of business; Charlotte Gilman's evolutionary approach to the gendered economy; Schumpeter's long waves and cycles of capitalist development; and J.M. Keynes's situating of capitalism as a monetary-production system. In this spirit, we can embrace Nicholas Kaldor's stylized facts; Fernand Braudel's events, conjunctures and the long duree; Angus Maddison's statistical trends; Gordon Childe's archeology; Immanuel Wallerstein's several instances of hegemony; Marilyn French's historical evolution of gender; Eric Hobsbaum's expansive history of capitalism; and David Christian's big history framework. ${ }^{2}$ We thus suggest that writers and editors not only (a) embed their topics in historical time and (b) scrutinize transformation through evolution and metamorphosis but also (c) utilize some of the narratives of historical-evolutionary political economy, as the list of the grand masters mentioned indicates. In the process, it is hoped that we will contribute to the emergence of our own grand masters of evolutionary political economy in the process of understanding and changing the world.

\footnotetext{
${ }^{2}$ My favorite two books on 'how to do evolutionary political economy', for specific topics, using the 'principle of historical specificity and evolution', are those by Suter (1992) and Wolfson (1994), on debt cycles and financial crises, respectively.
} 


\section{Objective five}

\section{1 (5) Developing trans-multi-interdisciplinary EPE plus links to IPE}

Some mention is made in various parts of the manifesto of using 'interdisciplinary' (pp. 1, 2, 3, 7, 8(twice)), 'transdisciplinary' (p. 2) and 'multidisciplinary' (p. 5) methods or perspectives. Reference is made to biology, physics, neuroscience, law, economic sociology, politics, international relations, cultural studies, mathematics and so on, as fields that often assist in studying EPE. Beyond that, not much is said. It should be emphasized that a core reason for mentioning trans-multi-interdisciplinary themes relates to the principle of interdependency (the circular part of CCC): that major topical problems and policies, such as the caronavirus crisis, crime and incarceration, income/wealth of nations, un(der)employment, plus climate change and declining biological diversity, involve issues that transcend single disciplines (see Bunge 2009). This suits political economy which has always sought to study problems and policies within this broad context of complex issues and multicausal processes.

Nonetheless, if one is serious about trans-multi-interdisciplinary issues, it is necessary to realize that this is a big issue and that the three types of 'extra-disciplinary' methods mentioned can be substantially different. No papers that I could find have explored in any detail the differences between these three types of perspectives in EPE, which is very much an emerging field. But there are plenty of papers in the general literature on these concepts, which may help potential REPE authors deal with the issue.

Some papers, and many online platforms, mention that 'political economy' is an 'interdisciplinary' study, usually without rigorous definitions or analysis. Mario Bunge (b.1919), arguably the greatest philosopher of science over the past 100 years, in contrast, details the nature of an interdisciplinary perspective, involving the use of two or usually more disciplines, on the basis of the view that real world problems transcend disciplinary boundaries. Hence his view that in studying the problem of crime and its alleviation, one of his favorite real world problems, it is necessary to include, at a minimum, aspects of jurisprudence, social psychology, socioeconomics and neuroscience (Bunge 2016: 399). In this case, the core vision is crime and its alleviation, and the materials are utilized as per how useful they are at scrutinizing the core issue. Interdisciplinary studies in this context thus utilize aspects of different specific disciplines to scrutinize real world problems. ${ }^{3}$

Transdisciplinary is defined by Darian-Smith and McCarthy (2017: 5) as an approach to science where there are no disciplinary boundaries in the study, as scholars examine real world problems, for instance, through the use of whatever tools are available, without specifically advocating (or acknowledging) boundaries to their analyses. Defined in this way, some definitions of areas that have become

\footnotetext{
3 In this context, Bunge (2016: 400) argues that neoclassical microeconomics is not useful for studying real world problems, even in conjunction with other disciplines (although the others may be useful), since it is a 'pseudoscience' that is 'harmful' to the social fabric.
} 
well-established so-called transdisciplines, such as 'ecological economics', appear logically contradictory. The very title, 'ecological economics' appears 'non-trans', but may be 'inter' or 'multi'. This criticism is reinforced by the definition of 'transdisciplinary ecological economics' provided by Erlwein et al. (2020:16) where 'The essence of transdisciplinary work is overpassing the boundaries of individual disciplines in the construction of new linguistics that set the background for the emergence of new concepts and ideas that can better answer the challenges that the current and future exercise of economics so urgently demands' (emphasis added). Contrary to their view, by emphasizing 'economics', this definition fits more specifically into the 'multi' category.

Multidisciplinary has been defined in many ways. For instance, one view in 'economics', especially inspired by J.M. Keynes, saw it as 'the integration of ideas, concepts, analytical tools and methodologies from various fields into the scope of one field, in order to enrich theory and gain a better, multilayered understanding of the phenomenon being researched' (Ioan-Damoc 2018: 272; emphasis added). This makes good sense: that multidisciplinary work focuses primarily on, say, a certain problem, utilizing a specific field of knowledge (such as 'economics'), by using also aspects of other fields of knowledge.

Viewed in this way, the three major forms of extra-disciplinary analysis that were mentioned in the manifesto all make good sense, and likely all three would be advocated variously by certain editors and writers in REPE now and into the future. The fact that interdisciplinary is mentioned so many more times than the others in the manifesto may indicate that the editors give a privileged position to the inter type of analysis, or more likely it represents the simple truth that inter is the more common form of expression of extra-disciplinary analysis, especially for certain forms of political economy (e.g. on departmental websites and other platforms). The title of the journal, REPE, suggests 'inter' or, much more likely given the definitions above, 'multidisciplinary' analyses.

Proactive editorial proposal five (A) This topic of trans, inter and multidisciplinary perspectives and methods is a large one and needs to be scrutinized further in the pages of REPE, as it does have important implications for the styles of EPE scrutinized in the journal, and the ways in which global-regional-national problems are investigated.

The principle of interdependency, in this case involving the interaction or intersection between (inter)disciplines, areas, studies and issues, is also relevant to another core issue touched on in the manifesto: the relationship between EPE and IPE. Much emphasis in this context is given to linking post-Keynesians and original institutionalists with IPE issues. The manifesto also alludes to expanding other fields of EPE with IPE: it could have been emphasized that all EPE schools, methods and fields need to deepen their analysis of international themes (e.g. global-regional distribution of power, geopolitics, international relations, trade, production, finance, conflict, health and governance). 
The editorial manifesto distinguishes between the presumed neoclassical-influence of US IPE and the more classical political economy (including Marx) influence of European (or British) IPE (based partly on the paper by Cohen 2007). This dichotomy may have some validity, but it is exaggerated (on balance). For instance, Higgott and Watson (2008), Ravenhill (2008) and numerous others, think it is 'a caricature', 'more imagined than real', vis-à-vis the real nature of IPE. Consider, for instance, two crucial elements of US IPE that have their roots or close approximations to some perspectives of Marx and Veblen.

First, there is the case of World-Systems Analysis (WSA), originating with Immanuel Wallerstein (1930-2019) and his colleagues originally from the Fernand Braudel Centre in Binghamton, New York (as well as 'world systems' without the hyphen). The WSA is probably the most important type of IPE linking to EPE, and it certainly has a strong influence from classical political economy (including Marx), perhaps because it is based in the USA (given the 1960s-1970s social movements there). Wallerstein and colleagues were influenced mostly by Fernand Braudel (1902-1985), one of the greatest historians of the last 100 years, who gave impetus to WSA before he died. From an IPE perspective, WSA made major contributions, most notably, to the hypothesis of the rise and fall of global hegemonies from Holland to Britain and the USA, and to the rise of China. ${ }^{4}$

Secondly, it has to be said that core themes of many other outstanding US IPE scholars, including Keohane (1984) and Krasner (1983), include work on global hegemony, which links discussions to the WSA, and their emphasis on the potentially stabilizing nature of institutions, evolving through time, which is very Veblenian in nature. The notion of global regimes, such as the money, oil, trade, production and military institutions and agreements, is a major contribution to institutional and evolutionary political economy that should have a big presence in REPE. We could thus link IPE with the other schools and influences of EPE, as per this objective but also objectives $1-4$.

Thirdly, some EPEs believe there are few linkages between heterodox economics and IPE, and that it is 'negligent' and 'damaging' to conflate the two (Chester and Schroeder 2016). A related issue is that IPE changes through historical time, and that one journal of IPE may differ substantially from another. For instance, especially since 2010, the Review of International Political Economy (RIPE), the IPE journal most closely associated with $R E P E$, has come under the greater influence of feminist/gender themes (due to Editorial changes), with many articles displaying an eclectic vision linking certain variously inter-trans-multidisciplinary methodologies with political economy and political sociology; while having some authors overtly influenced by original institutionalism, neo-Marxism, and neo-realism. The evolution of IPE, if RIPE is any indication, has been evolving rapidly and is certainly neither overtly subject to the 'British v. North American' dichotomy nor much interested in neoclassical economics. It seems to be much more eclectic,

\footnotetext{
${ }^{4}$ See, for instance, WSA research currently being published in the Journal of World-Systems Research, and earlier work being published in the Review (journal of the Fernand Braudel Centre for the Study of Economies, Historical Systems and Civilizations, at SUNY, Binghamton).
} 
inter-trans-multidisciplinary and problem centered, and thereby likely receptive to EPE influences, with a tendency not to use advanced mathematics or econometrics. ${ }^{5}$

Proactive editorial proposal five (B) In this context, perhaps it is better to argue, overall, that EPE should engage more with IPE: not so much that it engage with $R I P E$, although this is advisable, but specifically that it develop an ongoing and persistent engagement with global, international and regional problems linked to the following: geopolitics; international relations; climate change; crises and instabilities; money, trade and production; class, gender and ethnicity; commodity chains and production networks; wealth and income production and distribution. Applying its own principles and concepts to these global-regional issues would likely help REPE's long-term objectives of advancing the scientific status of EPE along several dimensions of time, space and motion.

\section{Objective six}

\section{1 (6) Investigating differences within evolutionary political economy}

Now, we introduce the sixth main objective of the journal, scrutinizing differences within and between the major schools and influences of evolutionary political economy. As the editors say:

Besides the research in each of these fields, it is [these] structured interaction processes discovering differences, complementarities, and convergences that will take place in $R E P E$ and guide its discourses and its pluralistic heterodox editorial policy (Cincotti et al. 2020: 4; emphasis added)

If we include complementarities and convergences in objective 3 , this sixth objective concerns isolating differences within and between the various trends of evolutionary political economy. For instance, concepts and principles do differ somewhat among the various forms of EPE. 'Complex systems' gives priority to the notions of emergence; different systems, subsystems and sub-subsystems; interdependency between systems; and the nonlinear relationship between variables. Original institutionalism centers on institutions, institutional systems, habits, norms and mores, instincts and the instrumental and ceremonial functions of institutions. Heterodox macro (e.g. post-Keynesian influences) is based on fundamental uncertainty, endogenous money, monetary systems of production and demand-based growth regimes. Neo-Schumpeterian PE involves the notions of systems of innovation, lags between

\footnotetext{
${ }_{5}$ Cohen (2017) still does, however, argue for what he regards as the currently operating dichotomy in IPE between conventional (USA) and critical scholars (though possibly not implicating recent trends in $R I P E$ ), and he blasts conventional scholars for ignoring critical analysts, while arguing forcefully for the need of IPE to concentrate on the big problems and issues of the world. He also implicates the obsession that some have with formal techniques for inhibiting advancement of this problematic (big problems and issues).
} 
invention and innovation, routines and norms, financing of innovative methods, monopoly and competition, plus explicit and tacit knowledge.

Feminist PE develops such ideas as gender, nurturance, domestic labor, equality of opportunity, patriarchy, glass ceiling, institutionalized discrimination, double day, non-dualism and pluralist methodologies. Neo-Marxist EPE applies concepts such as modes of regulation, social structures of accumulation, institutional evolution, phases of metamorphosis, regimes of exploitation, systemic circuit of social capital, fictitious capitals and the rate of profit to the transformation of capitalism since its inception. Ecological PE scrutinizes issues/policies of climate change, biodiversity, pollution, renewable resources and genuine progress vis-à-vis the precautionary principle, sustainability, coevolution and the multiple capital paradigm. Agent-based computation shares themes with other trends/schools, such as the principle of heterogeneous groups and agents which recognizes differences of class, gender, ethnicity, species and microeconomic role; bounded rationality, out-of-equilibrium dynamics and path dependency; plus network and circuit studies emphasizing interdependencies, critical nodes, matrices and positive (and negative) feedback processes.

Traditionally heterodox economics has been concerned with differences centered around Sraffian v. some other schools, Austrian v. other schools, and so on. But since the manifesto makes no reference to Sraffian themes, this will not be discussed here. Only one reference is given to Austrian economics (plus one to Hayek) in the manifesto, which is discussed briefly later in this paper. Above, we discussed differences where they are in some measure complementary. Here, though, we centre on two issues concerning potentially contradictory principles or themes, one concerning agent-based computation and the other possible anomalous evolutions of REPE into the long-term future.

On the first of these, there are potential differences between agent-based computation $(\mathrm{ABC})$ and Veblenian, feminist, and numerous IPE scholars. Many of the latter groups may not have heard of $\mathrm{ABC}$, or at least not know how it operates. Yet even a cursory examination of $\mathrm{ABC}$ reveals several similarities in ontology, if not in methodology, between $\mathrm{ABC}$ and most EPE schools and influences. Special reference is given by $\mathrm{ABC}$ to the relationship, at least in theory, between individuals, groups, environments and whole systems; the heterogeneous nature of agents (rather than the representative agent); the importance of emergence, complexity, path dependence and out-of-equilibrium dynamics; and bounded rationality, endogenous money, financial-economic instability and cumulative buildup of processes through time. These are very much within the corpus of evolutionary-heterodox themes.

It is also important to consider the degree of realism and complexity of ABC studies. Numerous post-Keynesians and neo-Schumpeterians may approve of the level of abstraction required of $\mathrm{ABC}$ to represent somewhat realistic environments in association with individuals, groups and organizations. It cannot be denied that some core real world dynamics are included in the simulations. As mentioned, however, numerous Veblenians, feminists and IPEs may baulk at the level of abstraction, mechanics and deviations from real world dynamics 'required' for these models.

For instance, consider the ABC paper on 'securitization and the business cycle' (Mazzocchetti et al. 2018), which scrutinizes the hypothesis of securitization, which is a method of agglomerating hundreds or thousands of mortgages in sets of 
securities, rating these securities and selling them on the market. As most readers will know, this process of securitization was implicated as a major cause of the subprime crisis in the USA and hence critical to the GFC that followed.

The paper in question sought to study the influence of loans and mortgage securitization on the volatility of business cycles, through the use of a large scale agentbased stock-flow consistent macro-model and simulator. It introduced into the model a financial institution which buys loan mortgages from banks and issues securitized assets and mortgage-backed securities. The main results of this paper are that, in the long-run, with restrained securitization, benefits can be positive for the economy, but excessive use of securitization can lead to high levels of bankruptcy and lower income.

Regarding the complexities of the business cycle recovery and boom of 2004-2007 and subprime crisis (2007-2009) in the USA, plus GFC in the global economy (2008ff), some evolutionary political economists may indicate the need for more complexity of model-simulation to reflect certain other institutional/agent dynamics. For instance, it may be considered crucial to embed the securitization process in the institutional and historical environment of US financial circuits, policy as well as international links to the circuit. Before and during the 2000s in the USA and much elsewhere there was generalized deregulation of finance (and other institutions), where many of the lessons of the past were ignored and earlier regulations negated. There were also bouts of financial 'innovation', where new techniques emerged and some old ones used more often. During 2004-2007 in the USA, there was recovery in the market that led to boom, especially in the housing market, with agents/groups taking on risky ventures. Securitization expanded as different classes of mortgages were bundled together and sold as a package (securitized), and the proportion of subprime mortgages (risky) in the bonds rose above fifty percent at the height of the boom.

For the subprime crisis, some crucial anomalies were including a lot of subprime (junk) mortgages in the securities, rating the securities low in risk and financial institutions lending to subprime mortgagees while ignoring the prudential rules of lending. Poor households were encouraged to borrow, while high interest rates did not kick in often until years later. There was poor communication and information flows between borrowers and mortgage brokers, between brokers and issuers of securitized bonds, and between underwriters and investors. The euphoric environment suddenly moved to crisis, as key elements of the environment endogenously generated high levels of uncertainty during 2006-2008 in the USA. Rising uncertainty was generated from the emphasis on velocity rather than quality of loans, the movement from conservative to market accounting, the increasing distance between underlying assets and instruments, calculative risk models ignoring systemic uncertainty during the boom, structured investment vehicles being used to hide critical assets and liabilities from balance sheet scrutiny, the abuse of credit default swaps leading to Lehman Bros insolvency and the securitized mortgage bonds infecting global circuits of finance (O'Hara 2009).

The ABC simulations abstracted from most of these processes while concentrating on lending decisions and the bundling of mortgages into securitized bonds. The analysis could thus have been more complex and realistic by incorporating more 
historico-institutional context behind mechanisms, which markedly increased the amplitude (height/depth) of the boom, subprime crisis and GFC. This particular ABC study may be said to not truly reflect the intensity of the uncertainties and complexities of the real world. Others may desire even further complexity to include more international and governance processes, etc. ${ }^{6}$

It is true that Hanappi (2017) argues that agent-based modeling (ABM) can perhaps potentially deal with upscaling socioeconomic problems from the micro- to meso- and up to macro-dimensions (p. 468), through the use of a 'very special type of ABM'; that it can also deal with issues involving 'large-scale social evolution' ( $\mathrm{p}$. 469 ), such as the evolution of classes through the interlinking of 'economic, political and ideological ... forces', and that this is the most 'ambitious' and 'noblest goal' which ABM may contribute to political economy. Grabner (2016) additionally argues that ABM potentially is able to accommodate pattern models, holistic perspectives (expressed through Mario Bunge's 'systemism') and evolutionary processes characteristic of original institutional economics.

If the theses of Hanappi and Grabner are promising, then it would help if ABC scholars crafted an article, specifically for $R E P E$, on the (a) nature and context of $\mathrm{ABCs}$, (b) an example of $\mathrm{ABC}$ in practice, but where (c) they pick an exciting real world problem, (d) attempt to endogenize as many variables as possible, (e) apply several EPE themes, concepts and principles, and most importantly, (f) embed a large degree of realism of the processes/mechanisms involved in the model/simulation and $(\mathrm{g})$ situated in history through evolution. They could choose, for instance, a problem such as the coronavirus crisis (see Kerr et al. 2020); the emergence of recovery, boom and subprime crisis in the USA, and GFC in the global economy (2003-2012ff); the development of the Great Depression of the late 1920s and 1930s (or that of the 1870s-1890s); the corporate crises in the USA of the early 2000s; climate change; rates of crime and injustice through incarceration of 'people of color' in various areas; sub-Saharan Africa's governance-standard of living anomalies in historical context; or a typical financial crisis based on empirics (see Wolfson 1994).

The critical 'thing' is to illustrate that ABC can effectively deal with a large scale macro-global, systemic problem, providing a good deal of its institutional-historical complexity, rather than merely a micro-meso one. It would help a great deal if the authors could, in addition, where possible, explain all the major aspects of the paper, including terms and techniques, assuming an evolutionary-heterodox economist (with little knowledge of $\mathrm{ABC}$ ) is reading the paper. If this could be done successfully, and refereed by potentially skeptical scholars, it would likely promote general objectives 1-4, 6 and possibly 5 (including some suggested modifications), as well as aiding the enrichment and broader acceptance of certain styles of ABC within EPE. ${ }^{7}$

\footnotetext{
${ }^{6}$ A similar potential problem regarding insufficient complexity and lack of real world historico-institutional conditions is also mentionable vis-à-vis other $\mathrm{ABC}$ models, such as the work of Raberto et al. (2019) concerning 'from financial instability to green finance in the Eurace model'.

${ }^{7}$ Perhaps $\mathrm{ABC}$ will resolve some of these issues in the forthcoming special issue of REPE, mentioned earlier in this paper, on 'Agent-based macroeconomics in era of global crises: innovative policy measures for an adaptive resilient economy'.
} 
Proactive editorial proposal six Relating to $\mathrm{ABC}$ but also other methods, themes, concepts and principles, the journal needs to encourage the submission of papers on the emergent (ontological) relationship between micro-, meso-, macro- and global real world processes in the generation of problems and policies, with major degrees of institutional-historical realism. In this context, $R E P E$ should critically examine the nature of and contrasts between emergence hypotheses and empirics of various micro-meso-macro-global styles, such as, for instance, those of Bunge (1998, 2003), Dopfer et al. (2004) and Elder-Vass (2010).

The second issue of differences between the schools and trends of EPE may sometime in the future lead REPE to evolve into quite a different journal to that envisaged in the manifesto. It has happened to many other journals, perhaps the classic being the Journal of Political Economy, which used to be a real journal of political economy, emphasizing the ideological and political nature of economies, and including many evolutionary and pluralist contributions. Through time, it became simply another orthodox journal of economics. One could imagine that, unless prudential measures are effective, REPE could in the very long-term, move in a similar direction in being mostly orthodox and even conservative in its economics, with little of its context resembling heterodox/pluralist evolutionary political economy.

One factor at play here is that it is legally independent of EAEPE (although informally associated). The second, more important, is that REPE could have path-breaking members of the heterodox-EPE community on its editorial and advisory boards, but because it is likely controlled from above, changing leading editorial personnel could lead to changes in its editorial objectives where different concepts and principles set the tone for publication, that eventually lead to changes in the editorial and advisory boards along similar lines.

Under these potential future new editorial relationships the themes that dominate its published papers may, for instance, centre on Austrian economics, new institutionalism, avant-garde orthodox economics, and functionalist complexity theory and ABC. Status quo apologetics, absence of structural contradictions (or emphasizing only policy contradictions), functionalist micro-meso relations, agent-based dynamics without conflicting groups and protection of vested interests rather than the common good, may become the rules, norms and routines of the essentially de facto 'new' journal (in the future), which may well be the prevailing mainstream. The editorial manifesto does mention the desire to eventually become the mainstream, but hopefully not within the context of crowding-out micro-meso-macro-global dynamics, neo-Veblenian political economy, post-Keynesianism, neo-Marxism and radical-feminism. Under this type of (mainstream) leadership, it could also become a vehicle for mechanical or obtuse mathematics, rather than pragmatic mathematics seeking to communicate about the contradictions of the actually existing (or realistically simulated) modern world.

Proactive editorial proposal seven The relative power of various schools of thought and trends of EPE should be assessed periodically in the pages of REPE, as independent refereed papers on critical and incisive renewal, progress and critique 
published in REPE in a timely fashion. This should be used as a tool for assessing the nature of power imbalances, functionalist ontology and editorial conservatism which will likely inhibit the realization of current (possibly with suggested modifications) objectives.

Proactive editorial suggestion eight To help with this, also as a prudential measure, it is proposed that every year (a brief report), every five years (a detailed report with action) and every ten years (a major review, report and action) the journal editors and associates should critically evaluate whether indeed REPE has sought to become a vehicle of enlightening criticism and shaking up the status quo, or whether it has, alternatively, become part of the vested interests, seeking power and prestige for its own sake. This could be done in association with discussions between the editors, the Boards, the (proposed) independent Ombudsperson and others. The results should also be published as normal routine in the pages of the journal, and encouraging responses (rather than having separate publication online, being sent to interested parties, and later forgotten about).

\section{Assessing, preventing, and reducing corruption of REPE's objectives}

I will briefly describe three main forms of systemic editorial corruption that tend to be generated by academic journals and their associated organizations, which may compromise REPE's objectives, and suggest the need for prudential measures to help prevent $R E P E$ from being taken over by such habits and institutions. However, note here that I am not discussing so-called 'predatory publishing', as I don't think this applies to this journal; but I am mentioning systemic forms of corruption that operate in probably most journals, to some degree, and that should be eschewed where possible. These are not mere individualized behaviors but institutionalized ones that tend to be repeated through habitual repetition, entrenched power structures and discriminatory behaviors. Note, however, I can find nothing specific on these forms of 'academic editorial journal corruption' (or similar phrases) in the literature and instead have to relate general corruption literature to academic journal editing issues. ${ }^{8}$

The first form that journal/editorial corruption takes is systemic nepotism (Sroka and Veinhardt 2020). This occurs when editors, writers, referees and/or associations cooperate (wittingly or emergently) to control a journal's content in a way that unjustly increases their publication rate (or power) in the journal at the expense of others. Some writers are effectively prevented from publishing in a specific journal

\footnotetext{
8 Since, in my extensive searches, I could find no specific references to 'editorial corruption' in the literature, the paper by O'Hara (2014) is used to analyse several different processes of systemic corruption that can be more directly applied to editorial processes at academic journals. I am, of course, not discussing general issues of ethics in journals. Rather I am specifically referring to 'academic editorial journal corruption'.
} 
(and being active in the organization), while others are encouraged, even though both groups have good claims to fair treatment. 'Due process' (for some), accountability and transparency are thus eschewed. Typically, this occurs when the journal in question has a relatively static personage among the editors and advisors, especially including editor, associate editors plus editorial and advisory boards (and those acting in organizational roles in linked associations). It also occurs when, even if there is a rotation of editors, mostly the composition of the whole board includes people from a specific geographical area (when the journal itself is supposed to be 'global', as $R E P E$ is), from a specific set of institutions (e.g. so-called elite universities), from a specific ethnic group (e.g. westerners/whites) and from a specific gender (e.g. men). Keeping the editorial board static, especially the leading editors, can reinforce these circular and cumulative tendencies to look after the interests of the 'in' group, at the expense of the 'outer' group, or the common good.

Already, I can see potential problems at $R E P E$ since, while it expresses 'globalness', the co-editors and editorial board includes scholars almost entirely from Western Europe and the USA; as is the so-called International Advisory Board (which includes a few also from Mexico/Brazil/China/Australia/Asia). While this may work in the short term, over time, the journal's editorial/advisory constituents will need to undergo much change. This includes seeking out outstanding scholars from Africa, the Middle East, South Asia and (Central/Southern) Latin America, especially those who (still) live there. If $R E P E$ really wants to promote progressive change that accords with its objectives, especially in promoting prosocial norms, including numerous editors and writers from Africa and elsewhere it is under-represented will be paramount. Promoting change in this context is one way this offshoot of EAEPE can reduce corruption and promote global development, as it moves from birth to maturity.

A second form of corruption that may easily occur at $R E P E$ if we are not conscious of the need to prevent it, or stamp it out if it does occur, is systemic fraud (Button 2011). The editorial manifesto alludes to six objectives it has promised to promote. If it publishes few papers along the lines of some of the six objectives (possibly including suggested adjustments), and makes little or no attempt to rectify the situation, then this is a core element of editorial corruption (fraud; which could be linked with nepotism).

One can easily see how such fraud might occur. One way is for the readers, writers, editors and advisors of REPE to commit to medieval scholasticism, obscure academia, functionalism and conservatism, such that they are not interested in critical problems that beset the world, and critical perspectives of scrutinizing the world and its problems. If the journal becomes an instrument of obscurantism and members merely climbing the hierarchy of academia or management, then this is likely to occur. Most orthodox journals do this through having many papers making slight adjustments to models, and models that have a questionable linkage to the big issues of the real world and its evolution through time.

A third form of editorial corruption is systemic 'technique/theory capture'. Analogous to 'state capture', those writing certain quantitative, mathematical, philosophical and conceptual papers are not required to explain their papers cogently so those not cognizant of the theory/methods used can understand them. If this is operational, 
the journal in question is implicitly giving such writers certain privileged asymmetric powers of status, mystification and non-transparency not given to others who are required to explain their arguments in some detail. ${ }^{9}$

$R E P E$ should decide which of two directions it takes. The first is a vehicle where every paper can easily be read by EPEs, whatever their concerns, much like the Journal of Economic Perspectives (JEP; with possible technical appendices). Papers in $J E P$ are very well written and easy to understand without sacrificing theoreti$\mathrm{cal} / \mathrm{statistical}$ detail. The second is where REPE publishes all sorts of papers, some general, some specific, some technical, some conceptual and some which are a combination of all of these. The second direction is the dominant tendency with papers so-far published in volume one of REPE, and is implied in the editorial manifesto.

One can, however, make the second type of journal more like the first $(J E P)$ by requiring those writing papers consistent with objectives to explain any difficult or unfamiliar technical, philosophical and conceptual details included, such that those not familiar can still follow the argument. This does necessitate some flair in being able to write/edit well, and explain technical, philosophical and conceptual details not usually discussed in summary form. I would hypothesize the benefits being well worth the effort. It may require a seventh objective of the journal: that papers be written in a style that can be understood by those who are not specialists in the specific area/method in question, including explaining technical details, philosophy and concepts in summary prose (and/or in an appendix; or a glossary) to promote communication and thus enhance transparency and readability of such papers.

Proactive editorial proposal nine A necessary condition for the objectives (possibly modified) of REPE to be at least partially realized is for editors, advisors, writers and referees to avoid substantial editorial corruption of the objectives. The editors and others should thus, as a prudential measure, consciously try and avoid engaging in editorial nepotism, fraud and 'technique/theory capture', and document issues relating to corruption in refereed papers published in the journal. It may also be useful for an independent Editorial Ombudsperson (or committee) to be established which deals routinely with these sorts of issues and (potential) editorial disputes.

Proactive editorial proposal ten All six or preferably seven objectives of REPE (with suggested deepening and modifying of objectives) should be kept at centre stage when editors, referees, committees and others are considering all papers, symposia, awards and special issues (to help prevent editorial corruption). Such analyses of objectives should become a progressive 'routine' (Attour and Lazaric 2020) among enterprising editors and writers. For instance, the editors/committees could draw up a matrix of the extent (1-10) to which all papers submitted and also

\footnotetext{
${ }^{9}$ One potentially (re)productive way of moderating some forms of editorial corruption is for REPE to develop an online tutorial system for referees and editors to improve their communication/diplomatic skills when refereeing papers. This could include 10 modules (M), including, e.g. possibly a method sequentially dealing with, re the first three modules, how to write: M1 = a general overview of a paper (to start the report); M2 = a summary of good points, M3 = a summary of improvements needed; and so on through to M10. Experienced and young referees could all benefit from this.
} 
published accord with all the objectives (considering suggested adjustments), which could be debated and the outcome put into practice. These and other issues could then be reviewed in suggested yearly, five-yearly and decadal reports the editors publish in the journal. These issues could be discussed in annual online/physical meetings of Editorial/Advisory Boards; or better still, annual lists of problems and issues to think about and act on where the Boards could reflect on these and reply. Questions could also be raised about adding (or modifying) objectives through time as the original objectives evolve, become realized and new options become available, while keeping to the guiding spirit of the original manifesto. ${ }^{10}$

\section{Conclusion}

The purpose of this paper has been to stimulate debate, discussion and publications about this close textual analysis of the 'editorial manifesto', including its list/analysis of the objectives of the Review of Evolutionary Political Economy, and the proactive editorial proposals for ways in which these objectives may be realized and/or modified within the pages of REPE. The original objectives of the journal, contextualized, include the following: to potentially integrate core aspects of the converging schools and trends to (re)construct an evolutionary political economy, through scrutinizing real world problems, issues and policies using various evolutionary themes and methods, including especially those of complex-systems and history, while studying the positive and negative elements of the processes-events, within a trans-, multi- and interdisciplinary micro-meso-macro-global context, and evaluating the differences within and between the various schools and themes.

The paper makes ten proactive editorial proposals for reviewing, enhancing and/ or modifying these objectives. It suggests four additional areas in which special issues can be undertaken through the application of core concepts and principles to big issues of the day. It argues for the need to scrutinize the relationship between complexity theory and the principle of circular and cumulative causation. It encourages research linking positive and negative processes of innovation and metamorphosis through the instrumental and ceremonial functions of technology and institutions. It suggests papers, symposia and special issues be encouraged on the different ways of scrutinizing the nature of change and metamorphosis within political economic systems, using complex-systems dynamics, especially historical analysis, and other quantitative and qualitative methods. It also proposes scrutinizing the nature of and differences between trans-, multi- and interdisciplinary dimensions, and that international political economy issues be analyzed by all schools and trends, within EPE.

\footnotetext{
10 The invitations for two of the special issues (SIs) I saw for the journal contained no specific mention of $R E P E$ objectives; although some could variously be construed as alluding to general objectives 1 and/ or 2 and/or 4. This is a missed opportunity. Also, the note about special issues on the REPE website suggests potential SI editors check out the 'Aims and Scope' document; but this is an inadequate document compared with the manifesto, even though the latter has its problems; hence this paper.
} 
The journal is said to need to encourage papers on the emergent relationship between micro-meso-macro-global real world processes in the generation of problems and policies, and for the relative power of various schools of thought and trends of EPE to be assessed periodically in the pages of the journal, to help reduce the extent of centripetal distributions of power between various interests. It recommends publishing refereed independent papers, as well as reports from editors, concerning editorial directions and problems to stimulate journal objectives (or modify them accordingly, while keeping to the spirit of the manifesto). It outlines forms of editorial corruption of objectives and how they may be prevented or moderated through prudential measures. There is the need to keep these objectives (including suggested modifications) firmly in mind when eliciting, refereeing and assessing papers, symposia and special issues. It proposes an independent Editorial Ombudsperson or committee, as well as yearly, five-yearly and decadal editorial reviews and reports concerning progress with objectives that will likely enhance the future reconstruction and development of evolutionary political economy.

Acknowledgements The author wishes to thank the Wolfram Elsner, two anonymous referees, and Jed Joseph Adel for comments and suggestions for the rewrite. The usual disclaimer applies.

\section{References}

Arestis P (2020) Productivity and inequality in the UK: a political economy perspective. Rev Evol Polit Econ 1(1):183-197

Arthur WB (1994) Increasing returns and path dependence in the economy. Michigan: University of Michigan Press

Attour A, Lazaric N (2020) From knowledge to business ecosystems: emergence of an entrepreneurial activity during knowledge replication. Small Bus Econ 54(2):575-587

Berger S (ed) (2009) Foundations of non-equilibrium economics: the principle of circular and cumulative causation. London \& New York: Routledge

Bernardo JL, Martinez FL, Stockhammer E (2016) A post-Keynesian response to Piketti's "Fundamental contradiction of capitalism." Rev Polit Econ 28(2):190-204

Bunge M (1998) Social science under debate: a philosophical perspective. Toronto: University of Toronto Press

Bunge M (2003) Emergence and convergence: qualitative novelty and the unity of knowledge. Toronto: University of Toronto Press

Bunge M (2009) Political philosophy: fact, fiction and vision. New Brunswick: Transaction Publishers

Bunge M (2016) Between two worlds: Memoirs of a philosopher-scientist. Switzerland: Springer

Button M (2011) Editorial: fraud, corruption and the financial crisis. Int J Law Crim Justice 39(3):137-139

Caldwell M (1977) The wealth of some nations: introduction to political economy. London: Zed Press

Chester L, Schroeder S (2016) Conflation of IPE with heterodox economics? Intellectually negligent and damaging. J Aust Polit Econ 75:153-176

Cincotti S, Elsner W, Lazaric N, Nesvetailova A, Stochhammer E (2020) Towards an evolutionary political economy. Editorial to the inaugural issue of the Review of Evolutionary Political Economy REPE. Rev Evol Polit Econ 1(1):1-12

Cohen B (2007) The transatlantic divide: why are American and British IPE so different? Rev Int Polit Econ 14(2):197-219

Cohen B (2017) The IPE of money revisited. Rev Int Polit Econ 24(4):657-680

Darian-Smith E, McCarty P (2017) Beyond interdisciplinarity: developing a global transdisciplinary framework. Transcience 7(2):1-26 
Dillard D (1980) A monetary theory of production: Keynes and the institutionalists. J Econ Issue XIV(2):255-273

Dillard D (1982) Rewriting the principles of economics. J Econ Issue XVI(2):577-585

Dopfer K, Foster J, Potts J (2004) Micro-meso-macro. J Evol Econ 14(2):263-279

Dosi G, Fagioli G, Roventini A (2010) Schumpeter meeting Keynes: a policy friendly model of endogenous growth and business cycles. J Econ Dyn Cont 34(9):1748-1767

Dow S (2020) Gender and the future of macroeconomics: an evolutionary approach. Rev Evol Polit Econ 1(1):55-66

Dugger WM \& Sherman HJ (2000) Reclaiming evolution: a dialogue between Marxism and institutionalism. London \& New York: Routledge

Elder-Vass D (2010) The causal power of social structures: emergence, structure and agency. Cambridge: CUP

Elsner W (2008) (Ed.) Varieties of capitalism and new institutional deals: regulation, welfare and the new economy. Cheltenham: Edward Elgar

Elsner W (2010) The process and a simple logic of 'meso': emergence and the co-evolution of institutions and group size. J Evol Econ 20:445-477

Elsner W, Heinrich T \& Schwardt H (2015) The microeconomics of complex economies: evolutionary, institutionary and complexity perspectives. Oxford: Academic Press (Elsevier)

Erlwein A, Oliva I, Funders F \& Donoso PJ (2020) Towards a transdisciplinary ecological economics: a cognitive approach. F Funders \& PJ Donoso (eds), Ecological economic and socio ecological strategies for forest conservation: a transdisciplinary approach focused on Chile and Brazil. Cham: Switzerland, Springer.

Farmer JD, Gallegati M, Holmes C, Kirman A, Ormerod P, Cincotti S (2012) A complex systems approach to constructing better models for managing financial markets and the economy. Eur Phys J Spec Topic 214(1):295-324

Foster J, Metcalf S (eds) (2001) Frontiers of evolutionary economics: competition, self-organization and innovation policy. Cheltenham: Edward Elgar

Fusfeld D (1988) Economics: principles of political economy, 3rd edn. Boston: Scott, Foresman \& Co

Grabner C (2016) Agent-based computational models-a formal heuristic for institutionalist pattern modelling? 12(1): 241-261

Hanappi G (2017) Agent-based modeling: history, essence, future. PSL Q Rev 70(283):449-472

Hanusch H, Pyka A (2007) Principles of neo-Schumpeterian economics. Cam J Econ 31:275-289

Higgott R, Watson M (2008) All at sea in a barbed wire canoe: Professor Cohen's transatlantic voyage in IPE. Rev Int Polit Econ 15(1):1-17

Ioan-Damoc A (2018) Multidisciplinarity in economics education and how it can shape economic thinking in the future. Proceedings of the $12^{\text {th }}$ International Conference on Business Excellence 12(1): $263-275$

Jennings A, Waller W (1991) A feminist institutionalist reconsideration of Karl Polanyi. J Econ Issue 25(2):310-321

Jo T-H, Chester L, D'Ippoliti C (eds) (2018) The Routledge handbook of heterodox economics. London: Routledge

Keohane RO (1984) After hegemony: cooperation and discord in the world political economy. Princeton: Princeton University Press

Kerr CC, Stuart RM, Mistry D, Abeysuriya RG, Hart G, Rosenfeld K, Selvaraj P, Nunez RC et al (2020) Covism: an agent-based model of Covid-19 dynamics and interventions. Medmix: preprint server health sciences

Krasner SD (1983) International regimes. Ithaca \& London: Cornell University Press

Lazaric N, Pridico P \& Fadda S (Forthcoming) Governing structural change and sustainability through (new) institutions and organizations. J Evol Econ

Lee F (2008) A comment on "the citation impact of Feminist Economics". Fem Econ 14(1):137-142

Lee F (2018) Microeconomic theory: a heterodox approach. London \& New York: Routledge. Edited by Tae-Hee Jo

Marx K \& Engels F (1847-48) Manifesto of the communist party. Harmondsworth: Penguin, 1967

Mazzocchetti A, Raberto M, Teglio A, Cincotti S (2018) Securitization and business cycle: an agentbased perspective. Ind Corp Chan 27(6):1091-1121

Mills CW (1959) The sociological imagination. Harmondsworth: Pelican, 1970

Nesvetailova A (2014) Innovations, fragility and complexity: understanding the power of finance. Gov Oppos 49(3):542-568 
Nesvetailova A (2005) Global finance: new thinking on regulating speculative capital flows. Hist Mat 13(1):171-182

Nesvetailova A, Palan A (2013) Sabotage in the financial system: lessons from Veblen. Bus Hor 56(6):723-732

Nesvetailova A, Palan A (2010) The end of liberal finance? The changing paradigm of global financial governance. Mill J Int Stud 38(3):797-825

Nilsson NJ (1982) Principles of artificial intelligence. San Francisco: Morgan Kaufman

O‘Hara PA (2001) Encyclopedia of political economy. 2 Vols. Oxford \& New York: Routledge. Paper Edition

O'Hara PA (2007) Principles of institutional-evolutionary political economy: converging themes from the schools of heterodoxy. J Econ Issue 61(1):1-42. https://doi.org/10.1080/00213624.2007.11506993

O'Hara PA (2009) The global securitized subprime market crisis. Rev Rad Pol Econ 41(3):318-314. https://doi.org/10.1177/0486613409336179

O'Hara PA (2014) Political economy of systemic and micro corruption throughout the world. J Econ Issue 68(2):279-308. https://doi.org/10.2753/JEI0021-3624480203

O'Hara PA (forthcoming) Principles of institutional and evolutionary political economy: applied to current world problems

Palley TI (2015) Money, fiscal policy and interest rates: a critique of modern monetary theory. Rev Pol Econ 27(1):1-23

Raberto M, Ozel B, Ponta L, Teglio A, Cincotti S (2019) From financial instability to green finance: The role of banking and credit market regulation in the Eurace model. J Evol Econ 29(1):429-465

Ravenhill J (2008) In search for the missing middle. Rev Int Polit Econ 15(1):18-29

Schumpeter JA (1912) The theory of economic development. Oxford: OUP, p 1978

Schumpeter JA (1947) Capitalism, socialism and democracy, 2nd edn. New York: Harper \& Row, p 1975

Rodney W (1972) How Europe underdeveloped Africa. Bogle-L'Ouverture Publications, London (in partnership with Tanzanian Publishing House)

Sroka W, Veinhardt JV (2020) Nepotism and favouritism: how harmful are these phenomena? Forum Sci Oecon 8(2):79-91

Stockhammer E (2013) The Euro crisis and contradictions of neoliberalism in Europe. Kingston University Economics Discussion Paper. London: Kingston University. (December.)

Stockhammer ER, Gouzoulis G \& R Calvert Jump (2019) Debt-driven business cycles in historical perspective: the case of the USA (1889-2015) and UK (1882-2010). Post Keynesian Economics Society Working Paper No 1907

Suter C (1992) Debt cycles in the world-economy: foreign loans, financial crises, and debt settlements, 1820-1990. Oxford: Westview Press

Tool M \& Bush DP (Eds) (2002) Institutional analysis and economic policy. Boston \& London: Kluwer Academic Publishers

Toporowski J (2020) Financialisation and the periodisation of capitalism. Rev Evol Polit Econ 1(1):149-160

Whalen C (2011) Financial instability and economic security after the great recession. Cheltenham: Edward Elgar

Wilber CK, Jamieson KP (1983) An inquiry into the poverty of economics. South Bend: University of Notre Dame Press

Wolfson MH (1994) Financial crises: understanding the postwar U.S. experience. Armonk: M. E. Sharpe. Second Edition

Woolley F (2008) Reply to Frederic Lee's comment on "the citation impact of Feminist Economics". Fem Econ14(1):143-145

Wray LR (2015) Modern monetary theory: a primer on macroeconomics for sovereign monetary systems, 2nd edn. New York: Palgrave Macmillan 


\section{Authors and Affiliations}

\section{Phillip Anthony O'Hara ${ }^{1}$}

$\triangle$ Phillip Anthony O’Hara

ohara.gperu@gmail.com

1 Global Political Economy Research Unit (GPERU), Perth, Australia 